\title{
MSRI-UP: Using Community and Connectedness to Increase Diversity in Mathematics
}

\section{Elizabeth Platt Hamblin}

In the disruption and uncertainty of the time we live in, hope and reassurance may be found in looking at the efforts of those who are-and have been-working to build a diverse, engaged community. The MSRI-UP program selected for the 2021 Mathematics Programs That Make a Difference Award by the AMS represents a profoundly successful, 14-year-long effort to do exactly that.

The concept underlying the MSRI-UP program seems simple: invite a group of 18 promising undergraduate math majors from diverse backgrounds-Black, Latinx, women, and other historically underserved populationsto a six-week-long summer research program with the goal of encouraging their interest in mathematics and laying a foundation for them to continue in the field after they graduate. The program is led by a similarly diverse team of dedicated mathematics professors, assisted by graduate students (some of whom already passed through the program themselves), so that the students have an array of advisors and mentors to turn to when they need a sounding board. Students spend the first week or two getting an intensive background in the mathematics concepts underpinning the theme-which changes annually based on the mathematics focus of program leaders and contributors-before breaking into groups of two or three students plus a graduate teaching assistant to address a specific research topic.

Elizabeth Platt Hamblin is a freelance writer and editor. Her email address is platthamb1in@gmai1.com.

For permission to reprint this article, please contact: reprint-permi ssion aams.org.

DOI: https://dx.doi.org/10.1090/noti2268

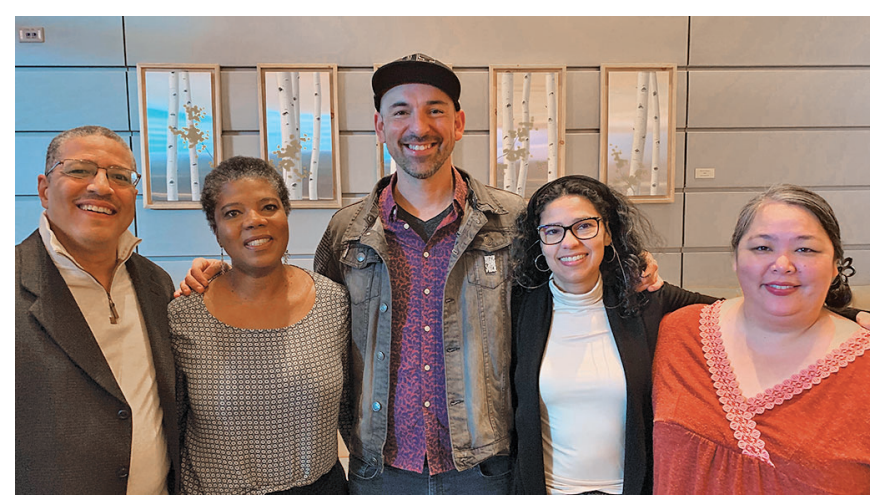

Figure 1. MSRI-UP directors Duane Cooper, SuzanneWeekes, Federico Ardila, Maria Mercedes Franco, and Rebecca Garcia at the Joint Math Meetings 2020.

It's pretty straightforward-basically another Research Experiences for Undergraduates (REU) program, right?

As all who've lived through 2020 should know by now, things are rarely ever as simple as they seem on the surface. And this is no exception.

On the surface, MSRI-UP might sound like the standard REU that many universities offer. But Suzanne Weekes, mathematics professor at Worcester Polytechnic Institute and the executive director of the Society for Industrial and Applied Mathematics, cofounded the program in 2007and from her perspective, it's much more than that. "I've run REU programs at my university, but it's not the same kind of experience," she observes, adding that the program creates a special, long-term connection between the directors, the graduate teaching assistants, and the undergraduate participants-regardless of whether the latter go on to 
graduate school. That bond can be a crucial turning point for many students who are on the fence about continuing into graduate programs when they enter MSRI-UP_or may not be thinking about it at all. When it comes to entering a career in mathematics, Weekes says, "if you don't have some measure of confidence or fortitude, it can be tough. We're there to give confidence and support." She adds that many of the students coming into this program experience "imposter syndrome," that is, they feel like they don't belong in a university setting or in advanced mathematics research. "We let them know they have a right to be in these spaces."

\section{Removing the Roadblocks}

One reason the program goes beyond the standard REU is that the program's directors are intentional about including students who may lack such encouragement and support in their home, their community, or their academic environment. MSRI-UP cofounder and Morehouse College mathematics professor Duane Cooper-who had the unenviable task of reconfiguring and running the 2020 program online through the upheaval of the pandemic-puts it this way: when selecting candidates for the program, the directors "look for a student who needs us more." Another director, Federico Ardila, a mathematics professor at San Francisco State University and an adjunct at the Universidad de Los Andes in Colombia, concurs: when it comes to selecting participants, "we look at what distance have they traveled-we're looking to build a community based on the personal journey. Who are the students who are not going to give up? Some of the students we accept know how to overcome hardship, where students who've had it easier might drop out faster."

Students who are the first in their family to attend college, for example, may feel pressured to leave school and get a job or switch to a major with assured employment after graduation-even if that direction is not the student's personal goal. Other, subtler pressures also may deter a student from pursuing a career in mathematics. Students of color may discover that pursuing a math major may

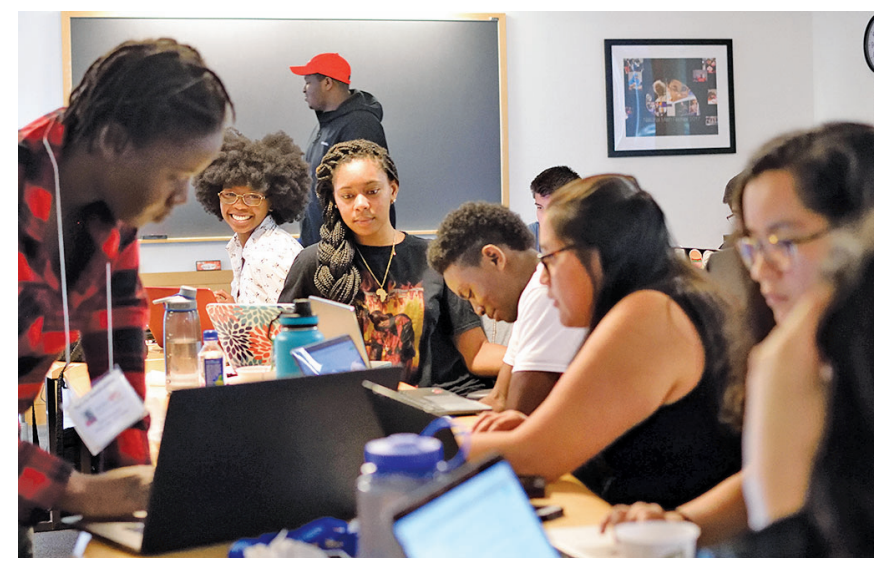

Figure 2. MSRI-UP 2018 students at work. place them in a university department comprised entirely of white, affluent academics who fail to understand or recognize the social or economic obstacles these students face. Weekes points out that such obstacles may be present even for students who are regarded as the best and the brightest - even students from highly touted academic institutions. "Some of these students will get into these universities, and people look at them and say, Damn, you're all set... but does that mean you feel included? That you are made to feel that you're part of the crowd? That you don't often wonder, what am I doing here? It's one thing to get into the school of your dreams, and another to feel welcome there." She adds, "Not to mention there are sometimes financial factors: schools can say we think you're bright, but guess what, you have to have a place to live, which means you have to work, and then time and finances are an issue."

\section{Modeling Mathematics for Underrepresented Students}

Even where that understanding exists, the absence of mentorship from math professors who've themselves lived such experiences may give their students of color the impression that they don't belong in the discipline. One MSRI-UP graduate, Dan Eckhardt, who was an undergraduate at Illinois Tech when he learned of the program at a mathematics conference, notes that until his participation in MSRI-UP in 2011, "being a person of color, at that point I hadn't directly seen someone like me being a mathematician. My school had plenty of people of color who were professors, but not in mathematics." Weekes recounts a similar comment from a Latino student in a group she led: "One student made a comment to me, "This is the first time I've had a Latino professor.' Because we're adults, it's possible to forget that we've had that experience long before in our own lives. The students are new; these are new experiences." The absence of such role models can be damaging to even the brightest and most promising students, says Weekes, noting that "not seeing yourself reflected in the world that you inhabit-you may unwittingly absorb that this is not the place for me, or this is not a goal for me."

Rather than lose such students to the strain of "going it alone" to pursue their love of mathematics, the MSRI-UP program offers them the support and guidance that will help them keep going-and expand their view of what a career in mathematics actually means. "One point to make clear: we're not necessarily looking for the top students according to the standard metrics. A lot of our students, when they apply to us, might have been turned down by a lot of [REU] programs. We're especially interested in attracting and supporting students who've never even heard of grad school," Ardila explains. Cooper adds that "even though individually, students can do what they want to do [in their future careers], our job is to make a mathematics career seem like something they want to do-and for those 
who already want to, the goal is to keep them on that path." Some of those benefits are outlined by MSRI-UP alum Eckhardt, who says the program gave him "an honest perception of grad school-the expectations, the reality, the application procedures, what to look out for, and what to expect. Also having peers from a similar background-that was what really helped me decide that I actually wanted to continue down this path and get a graduate degree and continue in the field."

The program also adds a rich set of experiences that go beyond the nuts and bolts of mathematics research to establish interpersonal connections and a sense of community among its participants-all its participants, not simply the undergraduates. The math itself is challenging, and the research theme changes from year to year, depending on who leads a given year's program; 2021's program focuses on parking functions, while prior years' programs addressed everything from coding theory (2009) to algebraic combinatorics (2013) to sandpile groups (2016); see Figure 3. Most of the students, and indeed some of the graduate TAs, lack familiarity with thematic concepts, so the program starts with a week (or more) tutorial to bring students up to speed and includes presentations from postdocs working in the topic area. But the math is not the only factor involved in preparing students for a career-and to this end, the program offers workshops on professional development opportunities, social gatherings, and weekend excursions to promote peer connections. These aspects give the students a preview of what becoming a professional working in mathematics entails-what it feels like to "arrive" after making the journey. And it offers the leaders, including a number of the program's alumni, the chance to meet and make connections to the next generation coming after them.

Alexander Díaz-López, a 2010 program alum who is now an assistant professor of mathematics at Villanova, says that when he first came to MSRI-UP as a University of Puerto Rico undergrad, "I had done an REU the year before, but I was not $100 \%$ convinced that I wanted a career in mathematics. My idea was well, if this works out, I

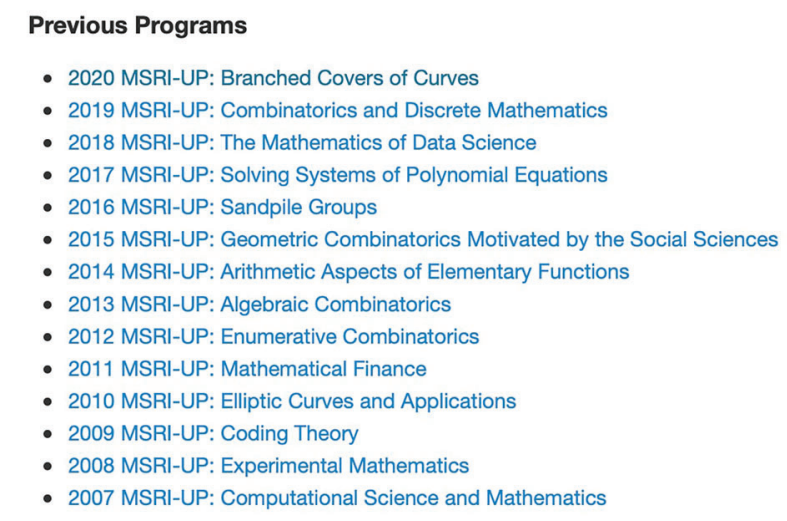

Figure 3. MSRI-UP programs from 2007-2020. guess I can come back to Puerto Rico and teach. I didn't have a sense that I could do mathematics at the highest level. From the program, I got that belief that yes, this can be my career, and I love this, and I'm going to push for this, and I have a support network." He considers "the community aspects, the connections I've made, the sense that I belong in this community, that there is a place for me in this community" to be some of the most valuable rewards of the MSRI-UP experience.

Even for its leaders, MSRI-UP is a gift that keeps on giving. Coming back as a graduate TA five years after his undergrad experience, Díaz-López unexpectedly encountered a different turning point. "For me, it was a summer where I got to be a TA and mentor students and meet all these amazing folks. I would've never imagined it would be the start of a research direction. The topic that we were doing research on, particularly one of the projects-we published a paper on it a couple of years later-it wasn't my main focus at the time. But then at this conference I'm attending, a master's student gives a presentation, and the topic is very close to what we covered at MSRI-UP." Díaz-López approached the presenter and introduced himself-and as a result, the student's advisor became one of his closest collaborators. That summer's research topic, originally an interesting tangent, became central to his research career. He notes that one of the students he supervised that year just finished his own PhD from Notre Dame-Díaz-López's own alma mater. "We've kept in contact through it all. [MSRI-UP] is a place that you never close the doors-it's such a great environment. It was very important for my career. Whenever they need me, I'm going to be there."

\section{Enabling Deeper Learning}

The surface impact of the program can be seen through its stats. An evaluation developed for MSRI that surveyed program alumni from its inception in 2007 through 2018 [1] found that $88 \%$ of respondents were from racial/ethnic groups underrepresented in mathematics-most being Latino/Hispanic, Black/Afro-Caribbean, or multiethnic. Fifty-five percent of respondents identified as male, $42 \%$ as female, and $1 \%$ as transgender. Most ( $80 \%)$ were math majors, but a few were in allied disciplines, such as computer science or economics. At the most basic level, then, the program reaches the students it's trying to help. But here's the critical point in the stats: for $60 \%$ of the participants, MSRI-UP was their first cohort-based training experience; for $41 \%$ of them, it was their only such experience.

This finding hints at a key reason for the program's success: it enables underrepresented students to have an opportunity to engage with mathematics and with the mathematics community in a deeper, more meaningful way than they may have ever experienced before, while at the same time providing a space specifically designed to give these students a sense of safety and belonging. The format 


\section{AMS COMMUNICATION}

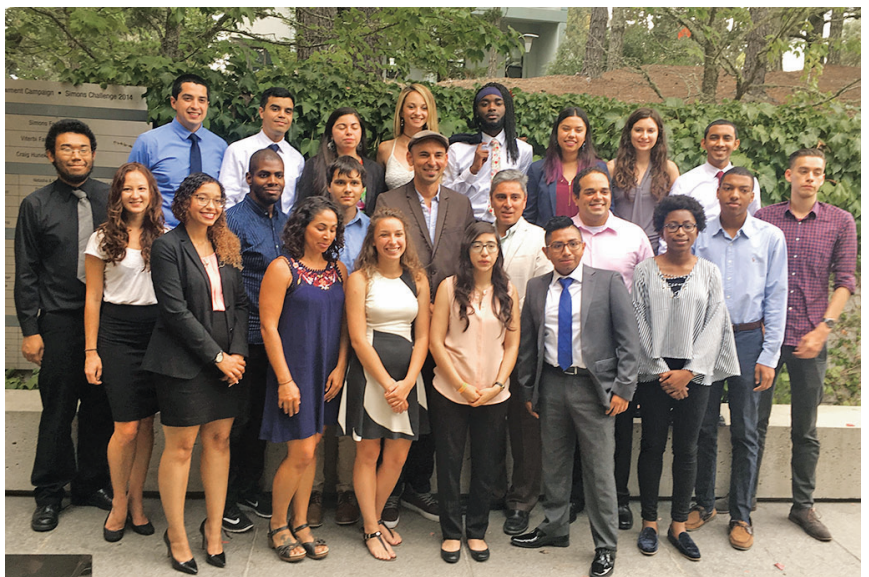

Figure 4. MSRI-UP 2017 students and mentors after their final presentations.

is consistent with what education experts call deep learning, which education researchers argue is imperative to keeping students engaged in the subject matter they're being taught. Educators Linda Darling-Hammond and Jeannie Oakes maintain that deep learning is "personalized" and can be "applied and transferred" from the academic environment to "real-world" settings [2]—which is where the long-term mentoring provided by directors and graduate assistants becomes essential. Darling-Hammond and Oakes also state that deep learning must be "equitable and oriented to social justice" through "an awareness of race, class, gender, and other social characteristics that shape student experiences" [2]. For the students in MSRI-UP, that awareness is expressed in the persons of the program leaders and assistants as well as the mission of the program itself, which is "to contribute significantly toward ... increasing the number of graduate degrees in the mathematical sciences, especially doctorates ... by cultivating heretofore untapped mathematical talent within the US Black, Hispanic/Latino and Native American communities" [3]. Ardila notes that "as a program, we're trusted in the sense that if a professor has been mentoring a student of color who wants to participate, [the mentors] know we can be a supportive environment and the student is going to get the positive reinforcement." He adds, "Who the mentors are is fundamental-we look for individuals who are really stellar researchers who are prepared to remain engaged long-term" to run the academic portion of the program. The bottom line is that having had the experience of engagement, of deep learning, it makes the students hungry for more-giving them incentive to keep going.

\section{A Sense of Balance}

It's important to bring a sense of balance to any endeavor if you want your students to stay engaged. In their 2003 book, The Power of Full Engagement, Jim Loehr and Tony Schwartz argue that the key factor lies in managing and releasing people's energy, and not about being "on" all the time [4]:

We must be physically engaged, emotionally connected, mentally focused and spiritually aligned with a purpose beyond our immediate self-interest. [Full engagement] means being able to immerse yourself in the mission you are on, whether that is grappling with a creative challenge at work, managing a group of people on a project, spending time with loved ones, or simply having fun.

The MSRI-UP program walks that fine line between intensity and fun. Eckhardt describes it this way: "It's intense, and it's a lot of work, but it's fun, because you have a lot of peers from very similar backgrounds who most of the time hadn't had that level of camaraderie that helps everyone succeed." The program's emphasis on group interactions, building relationships, and empowerment-not to mention the weekend excursions around the San Francisco Bay Area-provide opportunities (in non-pandemic years) for students to recharge even in a highly intensive learning environment.

\section{Seeing and Sustaining Student Outcomes- Even In a Pandemic}

For some students, there's an immediate impact on how they approach their undergraduate mathematics studies. Cooper recounts an experience in which a 2015 student's time at MSRI-UP made a noticeable difference in his performance when he returned to the university-so much so that his advisor reached out to Federico Ardila, whom he knew personally, to remark on it.

But those benefits can be short-lived. Weekes says it's not unusual for a student to leave the program at the end of July feeling "pumped" and full of confidence, "but when we all get together a few months later, they say, 'I'm not going to grad school'-their confidence is all gone. We encourage them and work on restoring that feeling." Eckhardt notes that this follow-up support is crucial to success. "Grad school in math is tough. I went through it, and I have friends who dropped out. MSRI-UP prepared me mentally and gave me the network of colleagues that could help me get through it."

Students aren't obligated to go on to graduate studies, as Cooper points out. "At our orientation session this past summer [2020], on the night before the program began in earnest, I was quick to say that the students should not feel bad if they didn't continue," he says. "Our job is to expose [students] to the possibilities, and we'd love to see it, but we are not going to be disappointed if they choose some other path. We consider ourselves successful by the overall number of underrepresented students who do go on to advanced graduate learning." 
The 2020 program led by Cooper was uniquely challenged by the emergence of the COVID-19 pandemic. When a program is centered around an in-person, interpersonal connection between people who'd never met, how do you establish those relationships and build those connections when the students, program directors, and graduate TAs must interact in virtual space instead? The 2020 program organizers- "braver souls than I," according to Weekes-persevered to hold the program remotely, solving the technical challenges on the fly. "We persisted during this time," Weekes says. "It wouldn't have been the end of the world if we'd put it off, but they kept students engaged, enthusiastic-and 18 students had the opportunity to grow, do math, build a network, and reach all the goals. But it was a horribly busy year." Ardila calls 2020 "surprisingly successful" despite the obstacles. "I did feel a sense of community that I did not expect with no personal interaction at all. It seems to work even with everyone in their own houses. It was clear that the students had really warm relationships and a good sense of community." Cooper agrees, noting that some aspects of 2020 wouldn't have been possible without the pandemic, such as graduate and career panels that were composed entirely of program alumni.

\section{Structured for Success}

A large part of the reason for the program's effectiveness is its leadership structure. The program's group of directors ensures that many hands are available to carry the load; although Suzanne Weekes has stepped down for 2021, there are still five directors, as new director Candice Price, a mathematics professor at Smith College, has stepped up to support the program moving forward. Ardila says that even though the program itself is six weeks in length, in practice, it's a year-round effort, with long-term follow up for all students who move through the program. "In the year after the program, we give students the opportunity to meet twice-we fly them all to the conferences and talk to them about grad school to give them a boost. Long term, we're able to provide letters and professional support." Much of this personalized support is possible only because of the rotating leadership model they use, with directors taking the lead of the program every five years. "One reason for rotating directorship, it makes mentoring more manageable for individuals," says Ardila. "Shared leadership can be really powerful. Once every five years, you have to do the job with a level of commitment to every single one of those students every year-it takes a lot of personal effort as well as organizational effort."

Cooper notes that this structure is made possible because of the mutual respect among the directors. "There was a picture of the founding directors, and another one of the current group; someone looked at those and remarked, you all look like you really like each other-and we do! We have a lot of respect for each other and each other's opinions, and that is a special relationship. It's been a fun working group. Some of the decisions we made early, we've been very pleased with, even just basic structure. We early on knew groups of three was the way to go forward. Eighteen is the program size-we discussed whether we should increase it, because we've got the applicants and we can get people in, but we felt really good about what we were doing with the capacity we had."

\section{Change Happens at the Speed of Trust}

The MSRI-UP program looks beyond helping individuals to a larger goal: promoting a sense of community and "pay it forward" among its participants-many of whom return to the program as graduate teaching assistants, presenters, and mentors to a future crop of undergraduate math majors. Ardila notes that "the impact we want to have-it's not just about them succeeding, it's about lifting up the community. If you're able to get through the door, you leave that door open and support other people coming after you. Now that you've had this opportunity, pass it forward." Cooper agrees: "The idea is that it's the global impact, not the individual."

Ardila sums up the MSRI-UP program as "a long-term, ongoing effort. There's a sense in mathematical programs that we have been sleeping on this, and we have to recruit diversity. If we're able to transform mathematical culture in this way, it's not only going to be beneficial for minorities and women-it's going to benefit everyone. But change happens at the speed of trust, so we're constantly reaching out."

ACKNOWLEDGMENTS. The author is deeply grateful to Dr. Federico Ardila, Dr. Suzanne Weekes, Dr. Duane Cooper, Dr. Alexander Díaz-López, and Dr. Dan Eckhardt for their contributions to this article.

\section{References}

[1] J. R. Evia, L. Jacobson, K. Martin, K. Ciccarelli, and K. Peterman, MSRI-UP evaluation report, Karen Peterman Consulting Co., 2019.

[2] L. Darling-Hammond and J. Oakes, Preparing teachers for deeper learning, Harvard Education Press, Cambridge, MA, 2019, pp. 13-14.

[3] MSRI-UP home page, https://www.msri.org/web/msri /education/for-undergraduates/msri-up.

[4] J. Loehr and T. Schwartz, The power of full engagement: Managing energy, not time, is the key to high performance and personal renewal, Free Press, New York, 2003, p. 5.

\section{Credits}

Figure 1 is courtesy of Suzanne Weekes.

Figure 2 is courtesy of Paul Samuel Ignacio.

Figure 3 was retrieved from https://www.msri.org/web /msri/education/for-undergraduates/msri-up.

Figure 4 is courtesy of MSRI staff. 